\title{
'It is like being put through a blender': inclusive research in practice in an Australian university
}

Cathy Vaughan, Sarah Khaw, Georgia Katsikis, Jacinta Wheeler, Jasmine Ozge, Vasiliky Kasidis and Lila Moosad.

Centre for Health Equity, Melbourne School of Population and Global Health, The University of Melbourne 3010.

\begin{abstract}
How can university-based researchers committed to a position of solidarity with, and activism alongside, people with disabilities maintain such a stance in the metric-driven environment of the modern university? How can the academy ensure there is the opportunity for people with disabilities to contribute to production of the knowledge in which they have most at stake, in a wider environment where access to basic services for people with disabilities is precarious? In this paper we draw on our experience as a team of university- and community-based researchers with and without disabilities to reflect on these questions, using a framework of reflexive solidarity to consider practical strategies for strengthening the relationship between disability activism and the academy.
\end{abstract}

\section{Key words}

Inclusive research; participatory research; health research; women with disabilities; solidarity; reflexivity 


\section{Points of interest}

\section{Points of interest}

- Partnerships between researchers with and without disability can generate important knowledge but are undermined when partners' employment arrangements and access to basic social services are insecure

- Research partnerships are strengthened by clearly identifying the power available to all partners, the costs associated with research for different partners, and ways these can be more equally shared

- Research partnerships are strengthened by university-based researchers taking practical steps to increase access to university settings

- Research partnerships are strengthened by co-researchers being willing to engage in activism in relation to disability as well as other sources of oppression

- There are unintended and potentially negative effects of participation as a communitybased researcher, and university-based researchers need to listen to people with disabilities about how these can best be redressed. 


\section{Introduction}

Much has been written about the importance of research on the experience of people with disabilities being done with and by people with disabilities (Nind, 2014; Walmsley \& Johnson, 2003; Zarb, 1992). Increasingly university-based researchers (with extensive, formal research training - and who may or may not have disabilities) work alongside community-based researchers with disabilities to undertake research that aims to generate policy-relevant knowledge about the lived experience of disability, disability services and disability-based discrimination.

While there is growing interest in inclusive approaches to research that are based on collaboration between university-based and community-based researchers, less has been written about the practical implications of such an approach in contexts of increasingly constrained resources in the university sector and austerity in the community sector. How can universitybased researchers committed to a position of solidarity with, and activism alongside, people with disabilities maintain such a stance in the metric-driven environment of the modern university? How can the academy ensure there is the opportunity for people with disabilities to contribute to production of the knowledge in which they have most at stake, in a wider environment where access to basic services for people with disabilities is precarious? What enables, or hinders, people with disabilities to meaningfully engage with researchers based in an academic environment? In this paper we draw on our experience as a team of university- and communitybased researchers with and without disabilities to reflect on these questions.

We are a group of seven women who came together to undertake research about the sexual and reproductive health of women with disabilities from a migrant or refugee background now living in Melbourne, Australia. Four of us identify as women with different types of disabilities, and 
five of us identify as first or second generation migrants to Australia. One of us has an ongoing position, another a fixed-term contract, and the rest of us have been employed casually by the University of Melbourne to undertake this project. We are women with diverse experiences of the academy, in different countries, as staff and students; we have different life experience, training, personalities, cultural backgrounds, and political perspectives; and our practical needs are highly varied. We recognise that our experiences and perspectives do not represent the experiences of all people with disabilities, or of all researchers, but we hope our reflections are 'useful to think with' for people working at the intersection of disability, activism and the academy.

\section{Inclusive research and the academy}

Over the last several decades, there has been a shift by many university-based researchers from seeing people with disabilities as the subjects of research, to instead conducting research with people with disabilities and supporting research led by people with disabilities (Nind, 2014). Inclusive research practices specifically seek to empower people with disabilities, appropriately access and represent their views, and ensure the development of respectful collaboration (Walmsley \& Johnson, 2003). Inclusive research examines issues that are meaningful and relevant to people with disabilities, as established before the research-design stage, and has outcomes of benefit to them (Durell, 2016; Humphrey, 2000; Nind, 2014; Walmsley \& Johnson, 2003).

Principles of an inclusive approach require people with disabilities having "advisory, leading and controlling, and collaborative" positions within a research study (Bigby, Frawley, \& Ramcharan, 2014, 3). People with disabilities are recognised as co-producers of knowledge and coresponsible for knowledge translation, disrupting the hierarchal nature of traditional research 
relations and dynamics (Durell, 2016; Nind, 2014; Walmsley \& Johnson, 2003). Indeed, for decades there have been calls in this journal and elsewhere to challenge the social relations of research production through the development of an emancipatory research paradigm (Oliver, 1992; Zarb, 1992). Such an approach demands that researchers without disabilities do not speak on behalf people with disabilities, but rather work alongside and support people with disabilities to exercise power and control in the research process. This can involve stepping back, being prepared to put what you think you know aside, deep listening, and being open to learning from all involved in the research encounter.

Academic researchers seeking to facilitate an inclusive process often draw on a wide range of practices described as 'participatory' or 'emancipatory' to shift the location of power within research processes towards members of those communities with the most at stake in the knowledge being generated (Vaughan, 2014). Participatory researchers recognise that expertise is not located in any one group, and that community members such as people with disability have expertise borne of lived experience (Evans, 2016; Gray, 2014). However, in his call for dialogical research, sociologist Arthur Frank problematises the fact that "young professionals are taught that in order to be recognised as professional, and to sustain the prestige of the profession in society, they must utter words that claim to be the last word" (Frank 2005, 967, italics original). This claiming of a professional monopoly on expertise is in contrast to principles of participatory co-production, and highlights an ongoing tension for participatory researchers based in universities, who operate in an environment where claiming and naming expertise is fundamental to career advancement and job security.

Researchers using participatory and inclusive practices are often motivated to generate knowledge that can inform disability activists' efforts to realise the social, economic and cultural 
rights of people with disabilities, and as such seek to conduct research that can directly address disadvantage and contribute to social change (Davis \& Vaughan, 2018; Wallerstein \& Duran, 2008). The current 'impact agenda' of universities around the world should, in theory, foster a supportive environment for research so explicitly aimed at social change. However, participatory researchers have highlighted that approaches to measuring and valuing research impact tend to prioritise scale and reach (Evans, 2016), privileging particular sources of evidence over the views of those directly affected by the research (Fine, 2012) - in this instance people with disabilities. The sources of evidence privileged in the measurement of impact put pressure on university- and community-based researchers alike to frame 'impact' in particular ways, and these may not make visible the social justice outcomes and realisation of rights prioritised by people with disabilities. In contrast to the power-sharing intent inherent in a participatory approach, Pain $(2014,20)$ argues that the measurement of impact may ultimately reinforce "hierarchal forms of power/knowledge relations within the academy, and between the academy and wider society".

Our experience of inclusive research in practice reflects some of these tensions; tensions as to whose experience and expertise is recognised, what types of experience and expertise 'count', what can be considered impact and from whose perspective. To think through these issues in this paper we draw on a framework of reflexive solidarity (Davis \& Vaughan, 2018).

\section{Reflexive solidarity}

The concept of reflexivity is well established in the social sciences, with Sandelowski \& Barroso $(2002,16)$ defining it as "the ability to reflect inward toward oneself as an inquirer; outward to the cultural, historical, linguistic, political, and other forces that shape everything about inquiry; and, in between researcher and participant to the social interaction they share". Participatory 
researchers have noted that a reflexive stance is central to ethical practice, enabling researchers to identify the power relations in which they are embedded and from which they make judgements (Banks et al. 2013), and to work towards rectifying power imbalances (Reid et al. 2018). This is particularly important when university- and community-based researchers come together to undertake collaborative inquiry about disability, given a history of the exploitation and abuse of people with disabilities, appropriation of the knowledge and labour of people with disabilities, and paternalism, tokenism and the imposition of top-down 'solutions' by researchers in the academy (Barton, 2010; Priestley, Waddington and Bessozi, 2010).

Solidarity, on the other hand, is less often explicitly noted as a foundational principle by university-based researchers, despite a rich history of research-in-solidarity by feminist scholars, anti-racist academics, and disability activist-researchers. Prainsack and Buyx $(2017,52)$ define solidarity as “an enacted commitment to carry 'costs' (financial, social, emotional or otherwise) to assist others with whom a person or persons recognise similarity in a relevant respect”. In framing 'similarity in a relevant respect', Prainsack and Buyx note that this is not necessarily shared lived experience, but rather that bonds of solidarity arise from our relational duties to each other, across difference, when there is a shared common purpose (Prainsack \& Buyx, 2017). When university- and community-based researchers come together for the shared purpose of coconstructing knowledge relevant to improving the circumstances of people with disability, this creates the opportunity for the development of relations of solidarity.

A framework of reflexive solidarity requires all involved in a research encounter to consider the 'costs' involved in participation, and how these may vary greatly for different actors (Davis \& Vaughan, 2018). Research conducted collaboratively by researchers with and without disability, with and without secure employment, with and without access to housing and other basic 
services, and who do and do not experience daily discrimination or privilege, will see the costs of engagement distributed in substantially unequal ways. Solidarity demands ally-ship, "making explicit that those in relatively powerful positions (such as professional researchers, funders, service providers and policy-makers) have a responsibility to critically examine power relations and share the costs of challenging disadvantage through their own commitments to action" (Davis \& Vaughan, 2018, 189). In the development of this paper, we have used this theoretical framework of reflexive solidarity to reflect upon our empirical experience of inclusive research in practice in the setting of an Australian university. We recognise that Australia has been spared many of the worst ravages of 'austerity' as currently experienced by our colleagues and peers in other countries, but we none the less work in a setting of increasing precarity, sustained cuts to university funding, and large-scale change in the delivery of services to people with disabilities that may resonate with readers in other locations.

\section{Research process}

The aim of this paper is to document some of our reflections upon and experiences of inclusive research in practice in an Australian university setting, with a view to contributing to debates about disability, activism and the academy. To develop the paper, we came together for a series of four workshop-style group meetings, each lasting approximately two hours in length, over the period May to August 2018. These meetings aimed to elicit reflection and discussion about our individual and collective experience of inclusive research in practice, with a focus on identifying

a) how university- and community-based researchers, with and without disability, experienced collaborative efforts to co-construct knowledge; b) aspects of the academic environment that undermine inclusive research practices; and c) strategies that strengthened each of our abilities to 
contribute to participatory and inclusive research in the academy. Our shared experience of undertaking a research project in 2017-2018 on the sexual and reproductive health of migrant and refugee women with disabilities (University of Melbourne ethics approval ID 1749277), underpinned discussions for the development of this paper. However, it should be noted that all of us have other experiences of collaborative, co-production of knowledge about the experiences of people with disabilities (see, for example, Warr et al. 2017; Vaughan et al. 2015; Vaughan et al. 2014) that also shape our perspectives.

At each workshop, two or more members of the team would take notes, detailing key points arising in our discussions. Records from group brainstorming activities (documented via white board) were photographed. We circulated these documents among the group, and through discussion of them at workshops and in between workshops at informal meetings or via email, decided upon the structure of this paper and the key reflections that we wanted to share, with the writing shared among co-authors.

\section{Inclusive research in practice}

Informed by a framework of reflexive solidarity, our discussions tended to return to questions of what solidarity actually looked like in the context of inclusive research practice. How could university- and community-based researchers, with quite different backgrounds and circumstances, come together in solidarity to undertake research? What would that involve? We identified three key themes in our discussions, which we outline below.

\section{Practical solidarity}


The notion of solidarity invokes the requirement of mutual support and cooperation among a group of individuals in order to achieve a common purpose. Mutual support needs to be based on an understanding of the individual and specific needs of group members, and for the entire group to be willing to accommodate those needs. In the case of partnership between universityand community-based researchers, this requires that academics bear the costs of ensuring that the university setting is accessible to people with disabilities. It also requires that community-based researchers are aware of the pressures on, and particular circumstances of, their university-based colleagues.

In a group such as ours, the diversity of our disabilities meant that our needs, both practical and emotional, were highly varied and that accessibility had an individual meaning for each one of us. One group member has a hearing impairment and was in practical need of note takers and meeting rooms with hearing loops, another with a physical disability needed wheelchair access. One group member was experiencing precarious housing and homelessness throughout the research period, which significantly undermined her physical and mental health. In order to facilitate full participation and inclusion in the research process for all group members, we each needed to invest time and effort to understand our colleagues' needs and identify ways to overcome barriers. Sometimes we got this right - but on other occasions we found that 'accessible' bathrooms actually weren't, double doors that should have facilitated wheelchair access were partially locked, and that rooms with hearing loops were booked out long in advance. The availability of individuals' time and energy fluctuated in line with unpredictable changes in health status and personal circumstances, and the more predictable deadlines associated with end of semester and project milestones. Patience was required all round. 
Evans $(2016,219)$ states “research may have unintended 'impacts' on the lives of those we work with which cannot always be anticipated". We would suggest that these unintended impacts extend to the effects inclusive research practice can have on researchers, wherever they are based, themselves. In working towards a shared purpose, and creating bonds of solidarity, members of our team found themselves 'opening up' and discussing matters with colleagues whom they did not know well outside the work environment. This puts individuals in a vulnerable position. Practical solidarity in this instance means the university-based researchers taking steps to ensure that all team meetings are held in a safe and private environment. Similarly, a range of emotional issues can arise for researchers during their interactions with research participants (in this instance migrant and refugee women with disabilities who were sharing experiences related to their sexual and reproductive health, including experiences of violence and discrimination). In addition to the potential for vicarious trauma arising from listening to participants' sometimes difficult stories, in our project there were occasions where community-based researchers would recognise similarities in their life experiences to those of participants, or discuss these during an interview. Such conversations tended to strengthen rapport and contribute to the generation of rich research data - but this came at a cost, borne by the community-researchers, when negative emotions were surfaced. Practical solidarity means that other members of the team, and in particular university-based researchers, need to be available to provide debriefing and psychological support whenever colleagues need it.

Janes $(2016,75)$ suggests that community-based researchers take greater risks and "no amount of acknowledgement, honoraria, good food, and other less tangible supports can begin to honor their contributions". For our team, risks included the emotional burden of hearing peers discuss difficult personal and private issues, particularly when there was similar life experience; the 
physical impact of participation which, depending on our different bodies, could include fatigue and pain arising from tasks such as typing, listening, reading papers, and travelling to attend meetings or data collection activities; the financial risk associated with receiving a salary from the university, which even when small and received on a casual basis, could jeopardise access to government benefits and support; and the hurt experienced when basic physical features of a university campus act to exclude some individuals but not others. There is nothing more unwelcoming than a door you cannot enter.

Practical solidarity requires that university-based researchers are aware of these risks. This, in itself, can pose challenges. Power imbalances associated with employment status, qualifications, age, and experience, as well as lived experience of discrimination and of having needs dismissed, can mean that community-based researchers can be reluctant to ask for what they need to facilitate full participation. However, a willingness to share costs must mean that the onus is on university-based researchers to make the effort to find out (Stack and McDonald, 2018).

\section{Political solidarity}

Political solidarity has been defined as a coming together in opposition to injustice or oppression (Scholz 2007). While there is certainly a history of exploitation of people with disabilities by researchers and other professionals, there is also a substantive tradition of researchers working together with disability activists to reveal injustice, challenge oppression, and advocate to improve the lives of people with disabilities. Political solidarity requires from university-based researchers a willingness to engage in activism, and to pursue concrete changes in the material circumstances of the lives of people with disabilities. 
Members of our group identified that there is a tension between an activist stance and working for a hierarchical institution such as a university. One of us asked "am I reinforcing those very power relations we try to equalise in participatory action research, through my participation in this institution? Have I become a sellout?’. While there was some ambivalence about engaging with the academy, others felt that the skills developed as a community-based researcher could strengthen future activism, including efforts to ensure the university setting itself was more accessible to people with different disabilities.

Our experience suggests a range of threats to political solidarity. Reynolds $(2013,64)$ notes that "potential allies fail because of ignorance, not reading the situation, fear of being wrong, political correctness, the 'politics of politeness', past harms, self-interest, indifference, being tired, or being busy". In addition we would add the impact of cuts to, or discrimination when accessing, basic services for people with disabilities. It is difficult to sustain the energy for activism towards change for a larger group when you do not have housing, are on a long wait list for assistive devices, or have spent hours of your day on hold while trying to speak to a government department by telephone.

Changes in the university sector over recent years also undermine political solidarity. Academics who are subject to disciplinary audits and rigid institutional timeframes (Pain, 2014; Williams, 2012), may worry about how undertaking the 'additional' tasks associated with activism may affect their employability if they have an impact on traditional measures of productivity. Members of our group noted that years of cuts in government funding to the tertiary sector had resulted in a casualised workforce, surveillance of researcher activity, and the privileging of particular types of academic output and knowledge. One of us asked how community-based researchers could act in solidarity with university-based researchers to advocate to the wider 
academy that inclusive and participatory approaches to research not be perceived as a 'touchy feely' endeavor, conducted by a sub-class of researchers, and that the impacts arising from inclusive research are genuinely important.

In our workshop discussions, group members repeatedly raised the importance of political solidarity, not just with other people with disabilities, but with people subject to racism, sexism, homophobia, institutional violence and, particularly in the case of Australia, with Aboriginal and Torres Strait Islander people and with people subject to discrimination and violence on the basis of migration status. Drawing on Audre Lorde (1982), group members emphasised that the struggles people live are not single-issue. Our research project examining participants' sexual and reproductive health at the intersection of their experiences of disability, migration and resettlement, and as women, reinforced our commitment to conducting research that can inform activism against multiple forms of oppression.

\section{Experiences of solidarity in action - an imperfect work in progress}

Our discussions and debates about inclusive research in a university setting surfaced a range of in-practice challenges that community-based researchers with disabilities experience in their engagement with the academy. One team member noted "It is like being put through a blender!" When asked to explain what this meant, she explained that prior to acquiring a mobility impairment she had worked as a health professional, trained to maintain strict boundaries between her professional and private life. However, when working as a community-based researcher doing research with other people with disabilities, these boundaries are lost. "It is stressful, it is confusing, it is tiring. There is no break or separation between work and the rest of life. The edges are all lost, there is no line". While one of our team felt that working as a community-based researcher with academic colleagues gave her a lens which helped her to 
frame her own story, the feeling of having been put through a blender, of having lost protective boundaries, was something that most of the team could empathise with.

As part of formal research training, researchers are often encouraged to 'set boundaries'. Students are firmly admonished not to become too close to research participants, ethics committees worry about 'dual roles' and slippage between positions of researcher, health professional (for example) and friend. However what does this mean for researchers who may be engaged to work on a particular project because of their 'dual' position? Peer research more broadly, and inclusive research specifically, is often predicated on the fact that researchers with disabilities are able to establish rapport with community members considered 'hard to reach' (or more accurately, easy to ignore), and that they will bring unique insights to the research encounter based on lived experience. However, while the engagement of community-based researchers can substantially enhance the depth and quality of a relevant research project (Nind, 2014; Walmsley \& Johnson, 2003), this comes with specific costs to the community-based researcher themselves. University-based researchers must be mindful of these costs, and the fact that the availability of financial, social, cultural and other resources that may offset the costs of participation in research will be unevenly distributed across the team. It is also important to be mindful that the benefits of participation in research - such as the development of practical skills, development of psychosocial resources such as self-confidence and expanded social networks, financial remuneration, employment opportunities, career advancement and enhanced social status - will also be realised unequally team members.

A reflexive approach to solidarity in practice requires co-researchers to be aware of the benefits they are accruing as well as the costs they experience in conducting research, to make these visible to the wider team, and to be willing to contribute to the redistribution of costs among 
team members. This does not mean colleagues without disabilities infantilising colleagues with disabilities or pretending that they can remedy entrenched structural disadvantage (such as the impact of austerity measures, or the lack of accessible housing in the rental market, for example). However, it does mean university-based researchers, particularly those without disabilities, thinking through - and asking specifically about - the potential for unintended negative impacts of inclusive research practices, and taking steps to minimise these to the greatest degree possible. Reflexive solidarity means providing concrete support to colleagues with disabilities, to ensure sustainability of participation and prevent burn out; accommodating the adjustments and modifications that are needed for equal engagement; establishing a team culture of respect and flexibility; and proactively challenging low expectations, where ever they are found. Ally-ship means a willingness to speak out, to listen and learn when you have made mistakes or misunderstood, and being open to trying new ways of working and collaborating.

Our experience as community-based researchers in the university setting was often one of having to work extra hard to prove ourselves and attain recognition, of consistently being underestimated, and of a lack of reasonable adjustments in the workplace. The fatigue arising from these daily workplace struggles should not be underestimated. Solidarity in action in response to such barriers to the academy requires researchers to undertake internal advocacy within the university, as well as externally. However when academics themselves experience precarious employment, this can limit their ability to do so.

A further challenge to solidarity in action that was identified during our workshops was the impact of the label 'community-based researcher'. While it was acknowledged that universitybased researchers have undertaken postgraduate study and have extensive training in relation to research, some of us noted that the label community-based researcher is underpinned by an 
assumption that researchers from the community (in this case women with disabilities) have not had such training. This is not necessarily the case. There is a substantial risk that people with disabilities engaging in researcher as community-based or peer-researchers, come to only be seen through the lens of their disability - that other aspects of these researchers' lives, experience and skills are rendered invisible. One of us highlighted that the hierarchical categorisation of our employment status with the university masked the fact that we are a team, with all team members making necessary and valued contributions without which the quality and impact of the work of the wider group would be lessened.

\section{Implications for the academy}

Reflection upon and analysis of our experience of collaborative, inclusive research in a university setting suggests that solidarity with researchers with disabilities will be supported by all members of the team taking practical steps to enable inclusion, recognising the political nature of working in solidarity, and expressing solidarity in action by addressing unintended negative impacts of participation in collaborative research.

University workplaces are often poorly designed and can fall short on even minimum standards of access for people with different types of disabilities. Allocating adequate time and securing the necessary resources to identify and redress potential environmental barriers to access - in preparation for inclusive research - will enable community-based researchers to better access the physical workplace and equipment, staff kitchen and toilets, and helps create a welcoming atmosphere. Addressing environmental barriers that undermine access to the university has long term benefits beyond the life of any specific research project, opening up spaces for staff and students with disabilities into the future (Liasidou, 2014; Stack and McDonald, 2018). Opening up physical spaces also increases the visibility of people with disabilities in university settings, 
and provides opportunities for increased incidental interaction between people with and without disabilities in the workplace. This can contribute to addressing the attitudinal barriers to the academy that arise from prejudice, fear and anxiety, and low expectations of the capacities of people with disabilities. Accessibility should be seen as an on-going project that benefits from the genuine collaboration of the whole research team, and should extend to advocacy about workplace conditions that impact all workers in universities in negative ways but disproportionally negatively impact workers with disabilities.

Other features of the university setting act as barriers to researchers with disabilities. The rigid timeframes, disciplinary audits, heavy workloads, and casualisation associated with contemporary academic life are difficult for all researchers, but particularly so for researchers with disabilities (Raymaker, 2017). Internal advocacy within the university is needed to support researchers with disabilities by making the adjustments and modifications necessary to accommodate individual circumstances (Raymaker, 2017; Stack and McDonald, 2018). This may include sourcing and funding assistive technologies and devices, adjusting elements of local work environments, and recognising that accommodating factors such as pain and fatigue requires flexibility with timeframes and using alternative approaches to communication, sharing information and meetings to enable colleagues to contribute even when unable to be physically present in the workplace. However, as Tregaskis and Goodley (2005) note, internalised oppression and feeling like you constantly have to prove your capacity can act to mean researchers with disabilities feel unable to ask for the reasonable accommodations to which they are entitled.

Practical solidarity means recognising that people with disabilities involved in academic research invest considerable emotional labour when sharing their personal lives and experiences with 
colleagues and research participants. This requires that all team members pay attention to the emotional needs that arise in the course of inclusive research projects, checking in regularly with colleagues with disabilities to debrief and giving us permission to step back if we need time out or to stop working for a period. After any specific research project it is important to keep community-based researchers engaged in the academic community, through invitations to events and providing opportunities to build on strengths and to share expertise and experience with others. This could involve engaging community-based researchers to give public lectures or participate in teaching students, and would help in maintaining newly established networks and visibility within the academy.

Solidarity also requires that university-based researchers recognise the harms and hurt that can be done to community-based colleagues if they are seen just through the lens of disability. In our team, some of us have disabilities, but we all identify in a range of other ways as well. In addition, we all have tertiary qualifications and have intellectual contributions to make, not just adding value through our 'lived experience' - and it makes us very uncomfortable when people assume our lived experience is representative of all people with disabilities, all migrant women, all academics (Raymaker, 2017).

Our experience of working as a team resonates with the notion of interdependence described by Tregaskis and Goodley (2005). While our different positions in the academy acted to categorise us hierarchically, the research would not have been possible without all team members' contributions, and this paper is based on interdependence. Recognition of this interdependence, and building the trust necessary to voice this recognition, was one of our first steps towards changing the social relations of research production as called for in the landmark special issue of this journal back in 1992 (Oliver, 1992; Zarb, 1992). However, a working environment of trust 
and interdependence is at odds with the move towards bureaucratic control and individual performance assessment seen in modern universities (Craig, Amernic and Tourish, 2014).

Changes in wider society have, as in many other industries, increased the precarity of employment in the tertiary education sector. This is certainly the case in Australia, where government announcements of cuts to university funding in recent years have been met with anger by university administrators (Pitman, 2018), and despair by an already highly casualised workforce (May, Peetz and Strachan, 2013). We recognise this is increasingly familiar to researchers worldwide. The challenge that workforce precarity presents for university-based researchers seeking to act in political solidarity with people with disabilities should not be underestimated. Increased policing of academic activism by university administrations and governments have placed pressure on researchers to not 'rock the boat'. Performance reviews for university-based researchers may not capture impacts of inclusive research that fall outside traditional, quantifiable metrics (Craig, Amernic and Tourish, 2014). This demonstrably increases pressure on researchers whose next contract may be tied to such specific performance metrics. In this environment it is important to highlight that political solidarity is a two-way street, with researchers with and without disabilities and based in different settings, needing to support each other to concretely demonstrate the value of this way of working.

After any specific research project it is important to keep community-based researchers engaged in the academic community, through invitations to events and providing opportunities to build on strengths and to share expertise and experience with others. This could involve engaging community-based researchers to give public lectures or participate in teaching students, and would help in maintaining newly established networks and visibility within the academy. 
In addition to supporting the research community, university-based and community-based researchers need to demonstrate political solidarity with all people with disabilities, recognising the diverse impacts of different types of impairment, and how these interest with other axes of discrimination. As researchers with and without disabilities, we feel a sense of accountability to the disability community. Despite the daily discrimination and struggles we may face, the position of researcher is a privileged one and we have an obligation towards our community to genuinely help improve things (Raymaker, 2017). Our community places trust in us and we don't want to break that trust. This means that we want to see actual tangible outcomes from the research we are part of for people with disabilities. Moreover, being heard in disability research is simply not enough. Change is the outcome we need, and this should be the aim of initiatives conducted in solidarity between researchers with and without disabilities (Davis and Vaughan, 2018; Higgins, 2016).

Solidarity in action requires a willingness to recognise and redistribute the costs associated with inclusive research practice, and to make visible in research the social and structural injustices affecting people with disabilities (Reynolds 2013; Prainsack \& Buyx 2017). It also involves understanding that as an ally you can (and will) sometimes be wrong about issues affecting people with disabilities. Rather than seeing this as a threat, reflexive solidarity involves recognising that misunderstandings can grow resilience, strengthen solidarity, empower resistance to injustices, and can also be humorous. Genuinely inclusive research involves dealing with difference, diversity and disagreement, not just between university- and community-based researchers, but also between people with disabilities (and between academics). People with disabilities are not a homogenous group, and bring contrasting perspectives, life experiences and experiences of disability to any research encounter. 
Facilitating an inclusive process must include creating the time and space necessary to negotiate difference.

\section{Conclusion}

It is well understood that people with disabilities need to lead activism about current struggles arising in contexts of austerity and precarity. Researchers can support this by working with activists to co-produce knowledge that can inform and underpin their efforts. Our experience as a team of university- and community-based researchers with and without disabilities suggests that reflexive solidarity is a useful framework for thinking through practice at the intersection of disability, activism and the academy. In environments where basic services are under threat, accessible housing scarce, and secure employment increasingly difficult to attain, it is imperative that researchers with and without disabilities create spaces in which they can work together to conduct research in support of disability activism. This will involve university-based researchers recognising the privilege they bring to the research encounter, for all team members to be willing to bear and redistribute the costs associated with participation in research, and integrating a position of patience, humour and hope with one of justified anger at the ongoing impact of prejudice and discrimination against people with disabilities. 


\section{References}

Banks, S., A. Armstrong, K. Carter, H. Graham, P. Hayward, A. Henry, T. Holland et al. 2013. "Everyday ethics in community-based participatory research." Contemporary Social Science 8 (3):263-77. doi: 10.1080/21582041.2013.769618.

Barton, L. (2010). "Response". British Journal of Sociology Education 31 (5):642-650. doi: $10.1080 / 01425692.2010 .500095$

Bigby, C., P. Frawley, and P. Ramcharan. 2014. "Conceptualizing inclusive research with people with intellectual disability." Journal Of Applied Research In Intellectual Disabilities: JARID 27 (1):3-12. doi: 10.1111/jar.12083.

Craig, R., J. Amernic, and D. Tourish. 2014. "Perverse audit culture and accountabiliyt of the modern public university". Financial Accountability \& Management 20(1):1-24. doi: 10.1111/faam.12025

Davis, E., and C. Vaughan. 2018. "Social action for social change " In Ethics in Participatory Research for Health and Social Well-Being, Cases and Commentaries edited by S. Banks and M. Brydon-Miller, 181-206. Abingdon: Routledge.

Dean, J. 1998. "Feminist Solidarity, Reflective Solidarity." Women \& Politics 18 (4):1-26. doi: 10.1300/J014v18n04_01.

Durell, S. 2016. "“Welcome to the real world” inclusive research with people with learning disabilities: A doctoral journey." The Qualitative Report 21 (12):2308-30.

Ellis, L. 2018. "Making decisions together? Exploring the decision-making process in an inclusive research project." Disability \& Society 33 (3):454-75. doi: 10.1080/09687599.2017.1392932.

Evans, R. 2016. "Achieving and evidencing research 'impact'? Tensions and dilemmas from an ethic of care perspective." Area 48 (2):213-21. doi: 10.1111/area.12256. 
Fine, M. 2012. "Resuscitating critical psychology for "revolting" times." Journal of Social Issues 68 (2):416-38.

Frank, A. 2005. "What is dialogical research, and why should we do it?" Qualitative Health Research 15 (7):964-74. doi: 10.1177/1049732305279078

Higgins, M. 2016. "Placing photovoice under erasure: a critical and complicit engagement with what it theoretically is (not)." QSE. International journal of qualitative studies in education 29 (5):67085. doi: $10.1080 / 09518398.2016 .1145276$

Janes, J. 2016. "Democratic encounters? Epistemic privilege, power, and community-based participatory action research." Action Research 14 (1):72-87. doi: 10.1177/1476750315579129.

Liasidou, A. 2014. "Critical disability studies and socially just change in higher education". British Journal of Special Education 41 (2):120-135. doi: 10.1111/1467-8578.12063

Lorde, A. 1982. "Learning from the 60s." In Sister Outsider: Essays \& Speeches by Audre Lorde, edited by A Lorde. Berkeley, California Crossing Press.

May, R., D. Peetz, and G. Strachan. 2013. "The casual academic workforce and labour market segmentation in Australia". Labour \& Industry 23(3):258-275

Nind, M. 2014. What is inclusive research? [electronic resource]: London : Bloomsbury Academic, 2014.

Oliver, M. 1992. "Changing the social relations of research production?" Disability, Handicap \& Society 7(2):101-114. doi: 10.1080/02674649266780141

Pain, R. 2014. "Impact : striking a blow or walking together?" ACME : an international e-journal for critical geographies. 13 (1):19-23.

Pitman, T. 2018. Higher education policy in 2018: Culture wars reignite, but in the end it's all about the money. The Conversation (Australia) sourced from https://theconversation.com/highereducation-policy-in-2018-culture-wars-reignite-but-in-the-end-its-all-about-the-money-109080 
Prainsack, B., and Buyx, A. (2017). "What is Solidarity?" In Solidarity in Biomedicine and Beyond edited by B. Prainsack and A. Buyx, 43-72. Cambridge: Cambridge University Press.

Priestley, M., L. waddington, and C. Bessozi. 2010. "Towards an agenda for disability research in Europe: Learning from disabled peope's organisations". Disability \& Society 25(6):731-746. doi: $10.1080 / 09687599.2010 .505749$

Raymaker, D. 2017. "Reflections of a community-based participatory researcher from the intersection of disability advocacy, engineering, and the academy". Action Research 15(3) 258-275. doi: $10.1177 / 1476750316636669$

Reid, A., J. Brown, J. Smith, A. Cope, and S. Jamieson. 2018. "Ethical dilemmas and reflexivity in qualitative research." Perspectives on Medical Education 7 (2):69-75. doi: 10.1007/s40037-0180412-2.

Reynolds, V. 2013. " "Leaning In" as Imperfect Allies in Community Work". Narrative and Conflict: Explorations in Theory and Practice 1(1):53-75

Sandelowski, M. and J. Barroso. 2002. "Finding the findings in qualitative studies." Journal of Nursing Scholarship 34 (3):213-20. doi: 10.1111/j.1547-5069.2002.00213.x

Scholz, S. 2007. "Political solidarity and violent resistance." Journal of Social Philosophy 38 (1):38-52. doi: $10.1111 / j .1467-9833.2007 .00365 . x$

Stack, E. and K. McDonald. 2018. " "We are both in charde, the academics and self-advocates": Empowerment in community-based participatory research". Journal of Policy and Practice in Intellectual Disabilities 15(1):80-89. doi: 10.1111/jppi.12236

Tregaskis, C. and D. Goodley. 2005. "Disability research by disabled and non-disabled people: Towards a relational methodology of research production". International Journal of Social Research Methodology 8(5):363-374. doi: 10.1080/13645570500402439 
Vaughan, C., T. Edmonds, S. Baker, M. Marco, J. Zayas, A. Devine, L. Gill-Atkinson, M Marella, Garcia, J., , J. Salgado, and C. Sobritchea. 2015. "W-DARE: A three-year program of participatory action research to improve the sexual and reproductive health of women with disabilities in the Philippines." BMC Public Health, 15 (984):1-7. doi: 10.1186/s12889-015-2308-y

Vaughan C. 2014. "Participatory Research". In Qualitative Research in Clinical and Health Psychology, edited by Rohleder P. and A. Lyons, 257-278. London: Palgrave MacMillan.

Vaughan C., Zayas J., Marella M., Edmonds T., Garcia J., Bisda K., Salgadao J., Marco MJ. 2014. 'Doing' Action Research: perspectives on rationale, rhetoric, reality and results. Development Bulletin, 76: $22-26$

Wallerstein, N. \& Duran, B. (2008). The Theoretical, Historical, and Practice Roots of CBPR. In Community-based participatory research for health: from process to outcomes edited by Minker M. and N. Wallerstein, 25-46. San Francisco, CA: Jossey-Bass.

Walmsley, J., and K. Johnson. 2003. Inclusive research with people with learning disabilities. [electronic resource] : past, present, and futures: Philadelphia, PA ; London : J. Kingsley Publishers.

Warr, D., H. Dickinson, S. Olney, J. Hargrave, A. Karanikolas V. Kasidis, G. Katsikis, J. Ozge, D. Peters, J. Wheeler, and M. Wilcox. 2017. Choice, Control and the NDIS: service users' perspectives on having choice and control in the new National Disability Insurance Scheme. Melbourne: The University of Melbourne.

Williams, G. 2012. "The disciplining effects of impact evaluation practices: negotiating the pressures of impact within an ESRC-DFID project." Transactions of the Institute of British Geographers 37 (4):489-95. doi: 10.1111/j.1475-5661.2011.00494.x

Zarb, G. 1992. "On the road to Damascus: first steps towards changing the relations of disability research production". Disability, Handicap \& Society 7(2): 125-138. doi: 10.1080/02674649266780161 